\title{
Palladium nanoparticles and nanowires deposited electrochemically: AFM and electrochemical characterization
}

\author{
Victor C. Diculescu • Ana-Maria Chiorcea-Paquim • \\ Oana Corduneanu • Ana Maria Oliveira-Brett
}

Received: 20 December 2006 /Revised: 10 January 2007 / Accepted: 11 January 2007 / Published online: 14 February 2007

(C) Springer-Verlag 2007

\begin{abstract}
Palladium nanoparticles and nanowires electrochemically deposited onto a carbon surface were studied using cyclic voltammetry, impedance spectroscopy and atomic force microscopy. The ex situ and in situ atomic force microscopy (AFM) topographic images showed that nanoparticles and nanowires of palladium were preferentially electrodeposited to surface defects on the highly oriented pyrolytic graphite surface and enabled the determination of the Pd nanostructure dimensions on the order of 50-150 nm. The palladium nanoparticles and nanowires electrochemically deposited onto a glassy carbon surface behave differently with respect to the $\mathrm{pH}$ of the electrolyte buffer solution. In acid or mild acid solutions under applied negative potential, hydrogen can be adsorbed/absorbed onto/into the palladium lattice. By controlling the applied negative potential, different quantities of hydrogen can be incorporated, and this process was followed, analysing the oxidation peak of hydrogen. It is also shown that the growth of the Pd oxide layer begins at negative potentials with the formation of a pre-monolayer oxide film, at a potential well before the hydrogen evolution region. At positive potentials, $\operatorname{Pd}(0)$ nanoparticles undergo oxidation, and the formation of a mixed oxide layer was observed, which can act as nucleation points for Pd metal growth, increasing the metal electrode surface coverage. Depending on thickness and composition, this oxide layer can be
\end{abstract}

Dedicated to Professor Dr. Algirdas Vaskelis on the occasion of his 70th birthday.

V. C. Diculescu · A.-M. Chiorcea-Paquim · O. Corduneanu •

A. M. Oliveira-Brett $(\square)$

Departamento de Química, Faculdade de Ciências e Tecnologia,

Universidade de Coimbra,

3004-535 Coimbra, Portugal

e-mail: brett@ci.uc.pt reversibly reduced. AFM images confirmed that the PdO and $\mathrm{PdO}_{2}$ oxides formed on the surface may act as nucleation points for Pd metal growth, increasing the metal electrode surface coverage.

Keywords Palladium nanoparticles and nanowires · AFM · Voltammetry · Impedance spectroscopy · Hydrogen · Oxide . Pre-monolayer

\section{Introduction}

In recent years, the study of phenomena and manipulation of materials at atomic, molecular and macromolecular scales, where properties can differ significantly from those at larger scale, has led to the design, characterization, production and application of nanostructures by controlling shape and size at the nanometer scale. Various materials such as nanotubes, nanoballs, nanodots and, in particular, nanoparticles [1-4 and the references therein] show an increasing interest due to their unique optical, magnetic, electronic and chemical properties, which may differ greatly from those of the bulk material. Nanostructured materials have a great increase of specific surface area [5] compared with the bulk material, and the intrinsic properties of a particular material may be changed when it is finely divided. In particular, the use of nanoparticlemodified electrodes presents advantages when compared with macroelectrodes: High effective mass transport catalyzes and controls the local environment [5]. Nanoparticlemodified electrodes allow convergent rather than linear diffusion, which results in a higher rate of mass transport to the electrode surface [6]. On the other hand, the catalytic properties of some nanoparticles cause a decrease in the overpotential needed for a redox reaction to occur [7]. 
Many metals have been investigated with respect to their possible role for nanoparticle and nanowire modification of electrode surfaces [8-10]. Among these, noble metals such as gold [11, 12 and the reference therein], silver [8-10, 13$15]$ or platinum $[8,9,16,17]$ have shown a greater stability, whereas nickel [18], copper [19,20] or iron [21] revealed some problems due to easy oxidation in solution or air.

Nanoparticle and nanowire formation of palladium are being investigated. A unique property of palladium among noble metals is its increased ability to adsorb, on its surface, and absorb, within its lattice, hydrogen, which gives palladium fundamental importance for many industrial processes such as catalysis, fuel cells, hydrogen storage and metal embrittlement [22].

Research on palladium electrochemical behaviour started about three decades ago and was carried out using palladium metal electrodes [23-28] or, more recently, gold $[28,30]$ or carbon electrodes [8-10,31-37] modified with palladium in different ways. Microscopy techniques, such as atomic force microscopy (AFM) and scanning electron microscopy have been used to investigate the surface morphology of graphite electrodes modified with electrodeposited palladium nanoparticles $[8,9,36,38]$ and nanowires obtained by electrochemical step edge decoration $[10,35,37]$.

Research on palladium electrochemistry can be divided into investigations concerning the interaction of hydrogen with palladium and those related to the kinetics and mechanism of palladium oxide film growth.

The complexity of palladium electrochemical behaviour in aqueous media is well recognized [31-35]. Among the possible reactions involved are: monolayer oxide formation, metal dissolution, oxygen absorption and hydrous oxide formation [23-25]. An important feature is that hydrous oxide formation initiates in a process referred to as incipient hydrous oxide formation or pre-monolayer oxidation that occurs at significantly more negative potentials than the potential required to initiate conventional monolayer oxide formation. Although the existence of this process was initially controversial, incipient hydrous oxide formation is assumed to play a major importance in electrocatalysis. The low potentials involved are attributed to the fact that the incipient hydrous oxide is confined largely to surface metals of low coordination number, i.e. adatoms. These adatoms lack the regular lattice stabilization energy, thus, becoming an active form of the metal, which can explain the unusual low potential.

Due to the controversial information concerning Pd behaviour at carbon electrodes, the present work deals with the voltammetric characterization of the processes involved in the redox processes of palladium nanoparticles and nanowires electrochemically deposited at glassy carbon electrodes. Magnetic AC Mode AFM (MAC Mode AFM) and impedance spectroscopy were also used for a better characterization of the processes involved during the formation and oxidation of Pd nanoparticles and nanowires at the highly oriented pyrolytic graphite (HOPG) electrode surface.

\section{Experimental}

Materials and reagents

Palladium(II) chloride, obtained from Sigma-Aldich, was used without further purification. A stock solution of $0.1 \mathrm{M}$ $\mathrm{PdCl}_{2}$ was prepared in $3 \mathrm{M} \mathrm{HCl}$ and slowly warmed up under continuous stirring conditions to dissolve and was stored at room temperature. Solutions of different concentrations of $\mathrm{PdCl}_{2}$ were prepared by dilution of the appropriate quantity in supporting electrolyte. All solutions were prepared using analytical grade reagents and purified water from a Millipore Milli-Q system (conductivity $\leq$ $0.1 \mu \mathrm{S} \mathrm{cm}^{-1}$ ).

Nitrogen saturated solutions were obtained by bubbling high purity $\mathrm{N}_{2}$ for a minimum of 10 min through solution and continuing with a flow of pure gas over the solution during the voltammetric experiments. The supporting electrolyte solutions are described in Table 1.

Microvolumes were measured using EP-10 and EP-100 Plus motorized microliter pippettes (Rainin Instrument, Woburn, USA). The $\mathrm{pH}$ measurements were carried out with a Crison micropH $2001 \mathrm{pH}-$ meter with an Ingold combined glass electrode. All experiments were done at room temperature $\left(25 \pm 1^{\circ} \mathrm{C}\right)$.

\section{Atomic force microscopy}

HOPG, grade ZYB of $15 \times 15 \times 2 \mathrm{~mm}^{3}$ dimensions, from Advanced Ceramics was used as a substrate in the AFM study. The HOPG was freshly cleaved with adhesive tape before each experiment and imaged by MAC Mode AFM to establish its cleanliness.

Electrochemical adsorption and deposition of palladium on the HOPG electrode surface were carried out in a onecompartment Teflon cell of approximately $12.5 \mathrm{~mm}$ internal diameter, holding the HOPG working electrode, on the bottom of the cell. A Pt wire counter electrode and an $\mathrm{Ag}$

Table 1 Supporting electrolytes, $0.1 \mathrm{M}$ ionic strength

\begin{tabular}{ll}
\hline $\mathrm{pH}$ & Composition \\
\hline 1.4 & $\mathrm{HNO}_{3}+\mathrm{KNO}_{3}$ \\
7.0 & $\mathrm{NaH}_{2} \mathrm{PO}_{4}+\mathrm{Na}_{2} \mathrm{HPO}_{4}$ \\
10.6 & $\mathrm{NH}_{3}+\mathrm{NH}_{4} \mathrm{Cl}$ \\
\hline
\end{tabular}


wire as quasi-reference electrode (AgQRE) were placed in the cell, dipping approximately $5 \mathrm{~mm}$ into the solution. The $\mathrm{AgQRE}$ electrode was calibrated against an $\mathrm{Ag} / \mathrm{AgCl}$ (3 M $\mathrm{KCl})$ reference electrode. Electrochemical experiments were carried out using a $\mu$ Autolab running with GPES 4.9 software, Eco-Chemie, Utrecht, The Netherlands.

Cyclic voltammetry $(\mathrm{CV})$ experiments used a scan rate of $\nu=100 \mathrm{mV} \mathrm{s}^{-1}$. The palladium nanoparticles and nanowires deposited using CV on the HOPG surface were gently cleaned with a jet of Millipore Milli-Q water and dried with nitrogen before being imaged in air.

The deposition of $\operatorname{Pd}(0)$ nanoparticles and nanowires on the HOPG surface from a solution of $100 \mu \mathrm{M} \mathrm{PdCl}_{2}$ in $\mathrm{pH} 7.00 .1 \mathrm{M}$ phosphate buffer, after application of a potential of $-1.00 \mathrm{~V}$, vs $\mathrm{AgQRE}$, during $30 \mathrm{~min}$ was also studied. The electrochemical cell with the $\operatorname{Pd}(0)$ nanoparticles and nanowires deposited on the HOPG surface was immediately transferred and mounted in the AFM microscope, and the AFM images were obtained in the solution of $\mathrm{PdCl}_{2}$.

AFM was performed with a PicoSPM controlled by a MAC Mode module and interfaced with a PicoScan controller from Molecular Imaging, Tempe, AZ. MAC Mode uses a solenoid placed under the sample to cause a magnetically coated AFM cantilever to oscillate near its resonant frequency. As it scans the sample, the AFM tip oscillates and touches the sample surface only at the bottom of this oscillation. All the AFM experiments were performed with a CS AFM S scanner with a scan range $6 \mu \mathrm{m}$ in $x-y$ and $2 \mu \mathrm{m}$ in $z$ from Molecular Imaging. Silicon type II MAClevers of $225 \mu \mathrm{m}$ length, $2.8 \mathrm{~N} \mathrm{~m}^{-1}$ spring constants and $60-90 \mathrm{kHz}$ resonant frequencies in air and $27-30 \mathrm{kHz}$ resonant frequencies in liquid (Molecular Imaging) were used. All images (256 samples/line $\times 256$ lines) were taken at room temperature; scan rates $0.8-1.6$ lines $\mathrm{s}^{-1}$. When necessary, MAC Mode AFM images were processed by flattening to remove the background slope, and the contrast and brightness were adjusted.

Section analyses were performed with PicoScan software version 5.3.1, Molecular Imaging and with Origin version 6.0 from Microcal Software, USA.

Voltammetric parameters and electrochemical cells

Voltammetric experiments were carried out using a Autolab running with GPES 4.9 software, Eco-Chemie, Utrecht, The Netherlands. Cyclic voltammograms (CVs) were recorded at scan rate $\nu=100 \mathrm{mV} \mathrm{s}^{-1}$, unless otherwise stated. The electrochemical impedance measurements were carried out by FRA software version 4.9. A root-meansquare (r.m.s.) and a perturbation of $5 \mathrm{mV}$ was applied over the frequency range $100 \mathrm{kHz}$ to $0.1 \mathrm{~Hz}$ with five frequency values per decade.
Measurements were carried out in a 0.5 -ml one-compartment electrochemical cell using a glassy carbon electrode (GCE; $d=1.5 \mathrm{~mm}$ ), with a Pt wire counter electrode and a $\mathrm{Ag} / \mathrm{AgCl}(3 \mathrm{M} \mathrm{KCl})$ electrode as reference. The GCE electroactive area was calculated to be $0.031 \mathrm{~cm}^{2}$ using a solution of $0.5 \mathrm{mM}$ hexacyanoferrate in $\mathrm{pH} \quad 7 \quad 0.2 \mathrm{M}$ phosphate buffer, using a value for the diffusion coefficient of hexacyanoferrate (II) of $7.35 \times 10^{-6} \mathrm{~cm}^{2} \mathrm{~s}^{-1}$ [39].

The GCE was polished using diamond spray (particle size $1 \mu \mathrm{m}$ ) before every electrochemical experiment. After polishing, the electrode was rinsed thoroughly with Milli-Q water for $30 \mathrm{~s}$; then, it was sonicated for $1 \mathrm{~min}$ in an ultrasound bath and again rinsed with water. After this mechanical treatment, the GCE was placed in buffer electrolyte and various CVs were recorded at $\nu=100 \mathrm{mV} \mathrm{s}^{-1}$ until a steady state baseline voltammogram was obtained. This procedure ensured very reproducible experimental results.

The deposition of $\operatorname{Pd}(0)$ nanoparticles and nanowires on the GCE surface from a solution of $100 \mu \mathrm{M} \mathrm{PdCl}_{2}$ in $\mathrm{pH} 7.00 .1 \mathrm{M}$ phosphate buffer saturated with $\mathrm{N}_{2}$, after application of a potential of $-1.00 \mathrm{~V}, \mathrm{vs} \mathrm{Ag} / \mathrm{AgCl}(3 \mathrm{M}$ $\mathrm{KCl}$ ), during $30 \mathrm{~min}$ was studied. Afterwards, the electrode was rinsed with deionized water and placed in the electrochemical cell containing only the chosen supporting electrolyte.

\section{Results}

\section{Redox behaviour of palladium chloride in solution}

The redox reactions of palladium on GCE were investigated by $\mathrm{CV}$ in $100 \mu \mathrm{M} \mathrm{PdCl}_{2}$ in $\mathrm{pH} 7.00 .1 \mathrm{M}$ phosphate buffer $\mathrm{N}_{2}$-saturated solution. Initially, the CVs were recorded over a wide potential range between variable negative potential limits and a positive potential limit of $+1.40 \mathrm{~V}$ at a scan rate $\nu=100 \mathrm{mV} \mathrm{s}^{-1}$.

The CVs were obtained starting at an initial potential of $0.0 \mathrm{~V}$ and scanning in the positive direction to the positive potential limit of $+1.40 \mathrm{~V}$. The scan was reversed to variable negative potential limits of: $-0.30,-0.60,-0.80$ or $-0.90 \mathrm{~V}$ (Fig. 1a). On the first and second CVs recorded, applying the negative potential limits of -0.30 and $-0.60 \mathrm{~V}$, respectively, no charge transfer reaction was observed during the negative- or the positive-going scans. On the third $\mathrm{CV}$, after reaching the negative potential limit of $-0.80 \mathrm{~V}$, on the reverse scan in the positive-going direction, a small peak $1_{\mathrm{a}}$ occurred at $E_{\mathrm{pa}}^{1}=-0.35 \mathrm{~V}$. In a further $\mathrm{CV}$ after switching the scan direction at $-0.90 \mathrm{~V}$, peak $1_{\mathrm{a}}$ occurred with a higher current. Thus, these experiments show that peak $1_{\mathrm{a}}$ only occurs after applying a potential more negative than $E \leq-0.80 \mathrm{~V}$.

Due to the complexity of the redox processes occurring at the GCE surface and to obtain information about the 


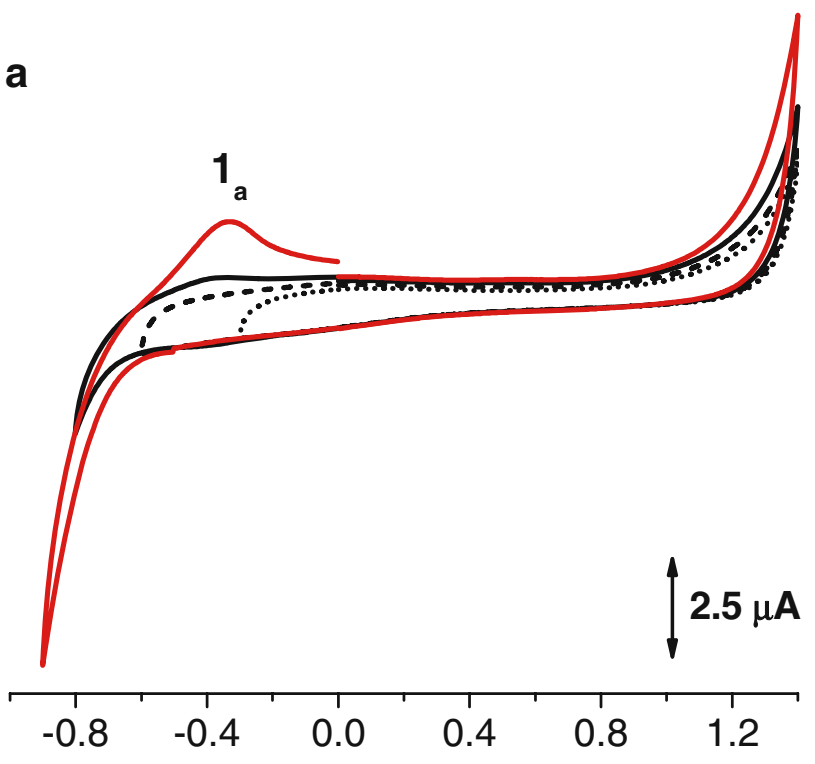

$\mathrm{E} / \mathrm{V}$ vs. $\mathrm{Ag} / \mathrm{AgCl}$

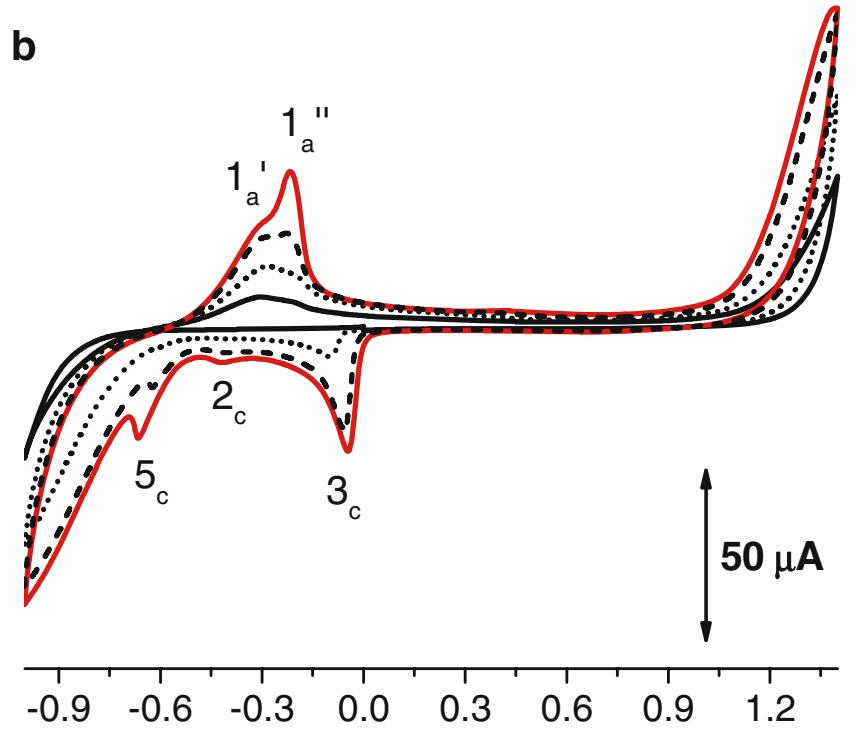

\section{E/ V vs. Ag/AgCl}

Fig. $1 \mathrm{CVs}$ of $100 \mu \mathrm{M} \mathrm{PdCl}{ }_{2}$ in $\mathrm{pH} 7.00 .1 \mathrm{M}$ phosphate buffer $\mathrm{N}_{2}$ saturated solution, $\nu=100 \mathrm{mV} \mathrm{s}^{-1}$. Initial potential $0.0 \mathrm{~V}$; positive potential limit $+1.40 \mathrm{~V}$ and negative potential limit: a $(\bullet)-0.30 \mathrm{~V}$, (--) $-0.60 \mathrm{~V},(-)-0.80 \mathrm{~V},(-)-0.90 \mathrm{~V}$; and $\mathbf{b}$ at $-1.00 \mathrm{~V}$ for the

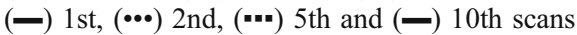

origin of these redox reactions, an experiment was performed using a clean GCE surface scanning between the positive potential limit of $+1.40 \mathrm{~V}$ and a negative potential limit of $-1.00 \mathrm{~V}$. The first negative-going scan obtained in these conditions (Fig. 1b) shows no welldefined cathodic peaks. During the first $\mathrm{CV}$, only the oxidation peak $1_{\mathrm{a}}$ was observed.

On the second $\mathrm{CV}$ scan, a cathodic peak $3_{\mathrm{c}}$ appeared at $E_{\mathrm{pc}}^{3}=-0.10 \mathrm{~V}$. Successive scans led to a considerable increase of the current of peak $3_{c}$, but the peak current stabilized after five consecutive scans. However, two more reduction peaks $2_{\mathrm{c}}$ and peak $5_{\mathrm{c}}$ were observed at more negative potentials with smaller currents. Moreover, after reversing the scan direction, on scanning in the positive direction, it was observed that the broad peak $1_{\mathrm{a}}$, which occurred on the first CV scan (Fig. 1a) now corresponds to an oxidation peak $1_{\mathrm{a}}^{\prime}, E_{\mathrm{pa}}^{1^{\prime}}=-0.31 \mathrm{~V}$, followed at more positive potentials by another peak $1_{\mathrm{a}}^{\prime \prime} E_{\mathrm{pa}}^{1^{\prime \prime}}=-0.21 \mathrm{~V}$. Also, increasing the number of scans, the anodic peak $1_{\mathrm{a}}^{\prime}$ became broader, and peak $1_{\mathrm{a}}^{\prime \prime}$ became higher and narrower. An increase of the capacitive current at very negative and very positive potentials was observed with the number of scans.

These CV experiments using a glassy carbon electrode immersed in a solution of $\mathrm{PdCl}_{2}$ clearly show that various palladium redox processes can occur. Based on the results already reported [23-35], the observed peaks can be related to the different possible palladium oxidation states such as $\operatorname{Pd}(0), \operatorname{Pd}(\mathrm{II})$ and $\mathrm{Pd}(\mathrm{IV})$ that undergo several redox reactions such as $\operatorname{Pd}(0)$ nanoparticles deposit, or $\operatorname{Pd}(0)$ oxidation to $\mathrm{Pd}(\mathrm{II})$ and $\mathrm{Pd}(\mathrm{IV})$ and palladium oxide formation.

\section{AFM characterisation of palladium nanoparticles and nanowires deposited electrochemically}

As demonstrated by electrochemical experiments, palladium nanoparticles can be deposited onto glassy carbon substrates forming films of different thicknesses. Early reports [40] have shown that depending on the $\operatorname{Pd}(0)$ film thickness, hydrogen could be incorporated into the palladium lattice formed on the substrate.

AFM was used to investigate the deposition of palladium on a carbon electrode surface. To understand the processes that take place at the electrode surface during the electrochemical experiments, the morphological characteristics of an HOPG electrode were characterized using MAC Mode AFM. In all AFM experiments, the HOPG substrate was used as working electrode because, in comparison with the GCE, it is extremely smooth, inert in air and has easy to clean terraces on its basal plane, characteristics that are an important advantage in studying the morphological characteristics of the palladium films. In fact, the GCE has a r.m.s. roughness of $2.10 \mathrm{~nm}$, and the HOPG electrode surface has a r.m.s. roughness of less than $0.06 \mathrm{~nm}$ for a $1,000 \times 1,000 \mathrm{~nm}^{2}$ surface area. As a control, CV experiments were performed using both GCE and HOPG electrodes, in a solution of $\mathrm{PdCl}_{2}$, and showed, as expected, an identical electrochemical behaviour.

The first approach was to analyse the palladium nanoparticles deposited on the HOPG electrode. The $\operatorname{Pd}(0)$ nanoparticles were deposited on HOPG from a concentrated solution of $1 \mathrm{mM} \mathrm{PdCl} 2$ in $\mathrm{pH} 70.1 \mathrm{M}$ phosphate buffer 
after performing five $\mathrm{CV}$ s recorded in the potential range of -0.50 to $0.00 \mathrm{~V}$, vs AgQRE, scan rate $\nu=100 \mathrm{mV} \mathrm{s}^{-1}$. The nanoparticles are formed at the negative potential due to $\operatorname{Pd}(0)$ electrochemical deposition. The AFM images were obtained ex situ after drying the sample as described in "Atomic force microscopy". Small Pd(0) nanoclusters were observed on the AFM images (Fig. 2a) with a linear arrangement on the HOPG surface, demonstrating de predisposition of the metal nanoparticles to preferentially attach to defects on the HOPG surface, such as step edges and lattice point defects. The small nanoparticles deposited on the HOPG step edges (Fig. 2b) had sizes of 12 to $26 \mathrm{~nm}$ height and 50 to $80 \mathrm{~nm}$ full width measured at half maximum height (FWHM).
Increasing the number of consecutive $\mathrm{CV}$ scans to 15 , no significant difference in the nanoparticle distribution on the electrode surface was observed. However, the dimensions of the three-dimensional nuclei increased to $25-40 \mathrm{~nm}$ height and 120-150 nm FWHM.

Ex situ AFM was used to observe the deposition of palladium obtained by $\mathrm{CV}$ recorded in a $1 \mathrm{mM} \mathrm{PdCl}_{2}$ solution, with the potential range between -0.50 and $+0.90 \mathrm{~V}$, vs AgQRE, scan rate $\nu=100 \mathrm{mV} \mathrm{s}^{-1}$. After five CVs, (data not shown), most HOPG step edges were filled with palladium nanoparticles of slightly larger dimensions, with $15-30 \mathrm{~nm}$ in height and 70-90 nm FWHM. Occasionally, very small fragments were imaged on the flat terraces of the HOPG. Considering the potential range
Fig. 2 MAC Mode AFM topographical images in air of palladium nanoparticles deposited onto HOPG from a solution of $1 \mathrm{mM} \mathrm{PdCl} l_{2}$ in $\mathrm{pH} 7.00 .1 \mathrm{M}$ phosphate buffer, by $\mathrm{CV}$, vs AgQRE, $\nu=100 \mathrm{mV} \mathrm{s}^{-1}$ : (a, b) after five scans between -0.5 and $0.0 \mathrm{~V} ;(\mathbf{c}, \mathbf{d})$ after 15 scans between -0.5 and $+0.9 \mathrm{~V}$. (e, f) Cross-section profiles through white lines in image $\mathbf{d}$
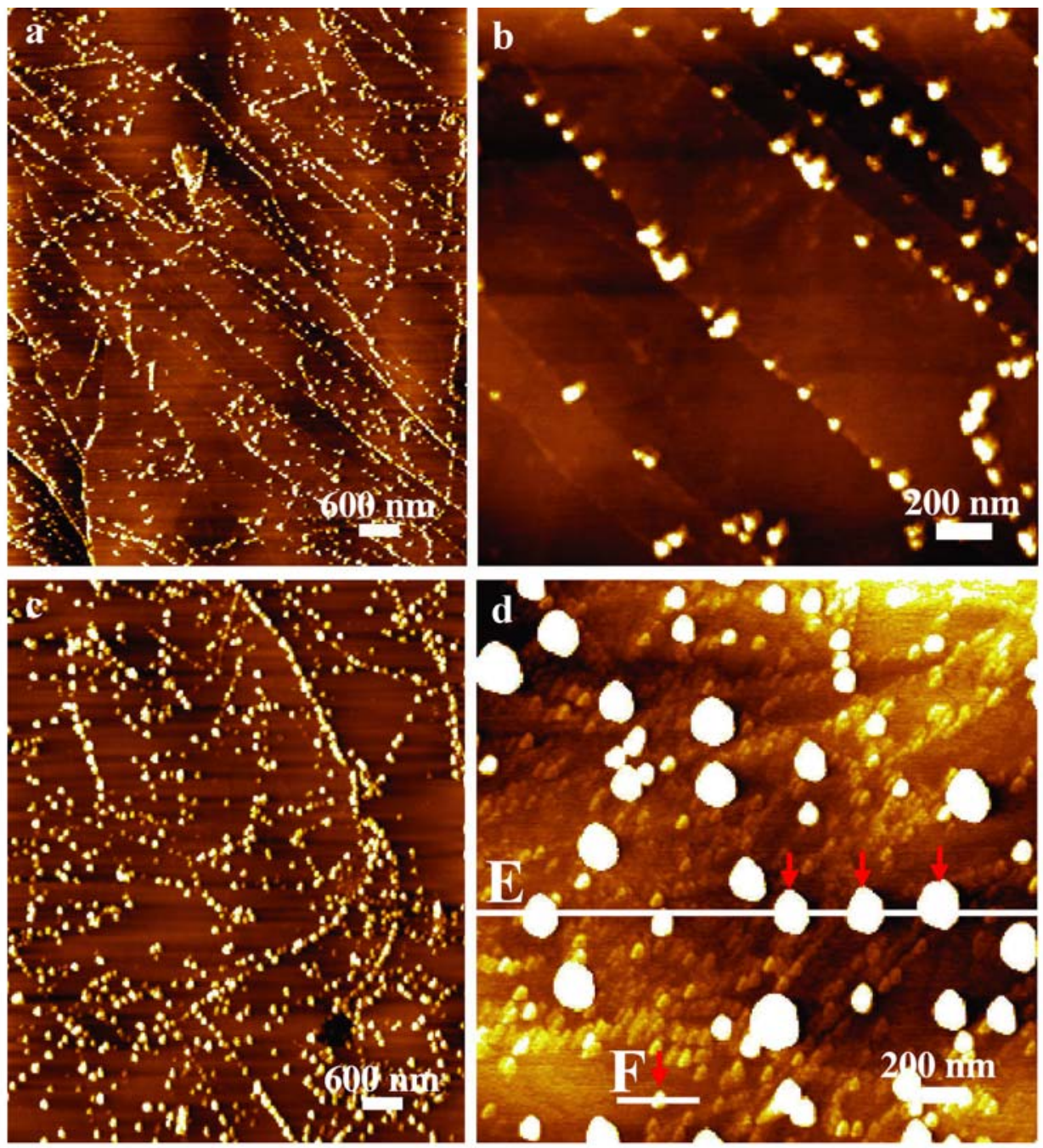

e
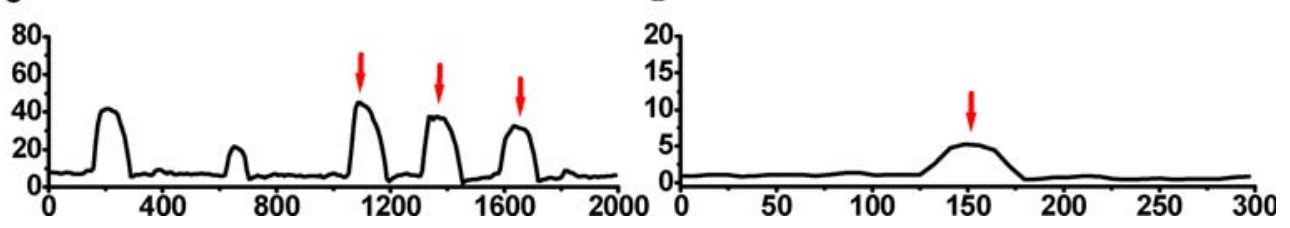
used, the nanoparticles formed are expected to be a mixture of $\operatorname{Pd}(0)$ and $\mathrm{Pd}$ oxides. After $15 \mathrm{CVs}$, two different adsorbed structures were clearly observed using highresolution AFM images (Fig. 2c and d). Palladium nanoparticles were deposited at the HOPG step edges, as well as randomly nucleated on the HOPG plane terraces, presenting dimensions of $17-50 \mathrm{~nm}$ in height and $100-130 \mathrm{~nm}$ FWHM (Fig. 2e).

In addition to the $\operatorname{Pd}(0)$ nanoclusters, very small fragments were observed in the images of $1-5 \mathrm{~nm}$ in height (Fig. $2 \mathrm{~d}$ and $\mathrm{f}$ ). These very small fragments are well distributed over the whole electrode in between the palladium nanoparticles. Due to the presence of the palladium nanoparticles, the surface observed by AFM is very rough. Consequently, the $z$-scale of the image had to be amplified for a better visual contrast between these two adsorbed structures.

However, the geometric parameters of the AFM tip still represent a limiting factor in the high-resolution investigation. For small palladium clusters, the AFM-measured width is larger than the real diameter of the deposit due to the convolution effect of the tip radius which is approximately $10 \mathrm{~nm}$. In these AFM experiments, different Silicon MAClevers were used, with unknown exact dimensions, being not possible to deconvolute the tip contribution to the AFM-measured particles diameter.

In another experiment, in situ AFM was employed to investigate the formation of $\mathrm{Pd}(0)$ deposits on the HOPG electrode (Fig. 3) using a solution of $100 \mu \mathrm{M} \mathrm{PdCl}_{2}$ and an applied negative potential of $-1.00 \mathrm{~V}$, vs AgQRE, for a
Fig. 3 a, b, d MAC Mode AFM topographical images in solution of $\operatorname{Pd}(0)$ nanoparticles and nanowires deposited onto $\mathrm{HOPG}$ from a solution of $100 \mu \mathrm{M} \mathrm{PdCl}_{2}$ in $\mathrm{pH} 7.00 .1 \mathrm{M}$ phosphate buffer by applying a potential of $-1.0 \mathrm{~V}$, vs AgQRE, during 30 min. e Amplitude image recorded simultaneously with the topographical image c. Digital zoom corresponding to the black quadrant in image d. c, f Crosssection profiles through white lines in images

$\mathbf{b}$ and $\mathbf{d}$, respectively
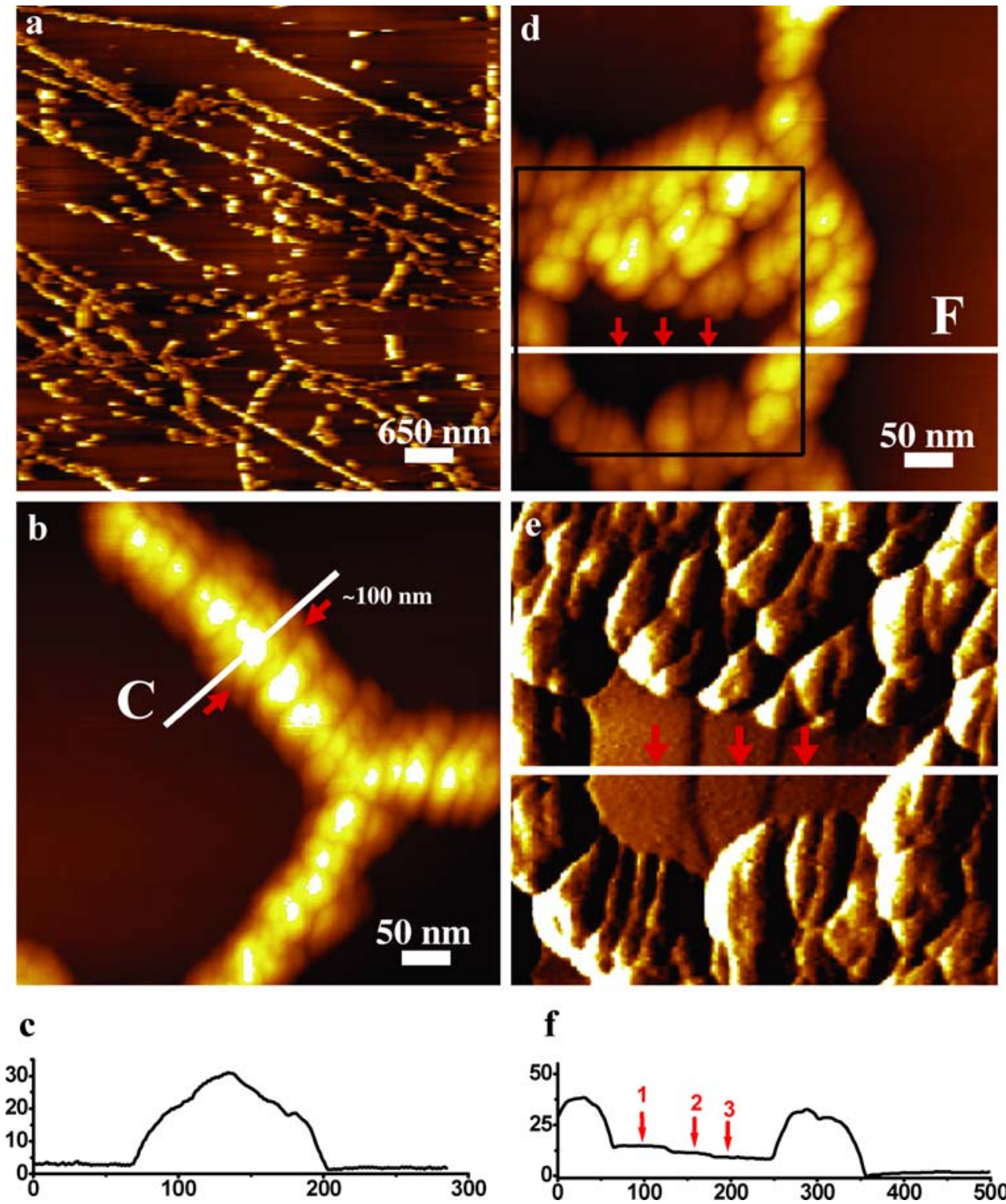
long incubation time of $30 \mathrm{~min}$. Short, as well as long, up to $7 \mu \mathrm{m}, \operatorname{Pd}(0)$ nanowires were observed on the HOPG surface step edges (Fig. 3a). The Pd nanowires showed ramifications after the changes in the direction of the HOPG step edges (Fig. 3b). High-resolution images clearly show a beaded morphology of the $\operatorname{Pd}(0)$ nanowires (Fig. 3b), each Pd nanowire being composed of a string of small nanoparticles of $20-60 \mathrm{~nm}$ in diameter. The height of the $\mathrm{Pd}$ nanowires measured by section analysis in the images was $27.8 \pm 4.6 \mathrm{~nm}$, and the FWHM between 50 and $120 \mathrm{~nm}$ (Fig. 3c).

When multiple defects were simultaneously present on the surface of the HOPG electrode, $\operatorname{Pd}(0)$ deposited in aggregates and looped filaments. In Fig. $3 \mathrm{~d}$ is shown the formation of such a complex structure, a ringed $\operatorname{Pd}(0)$ nanowire, with the nanoparticles joined together on its upper part forming an aggregate with the appearance of a honeycomb. The round nanowire is formed due to the presence of different closely disposed neighbour steps on the surface of HOPG.

The series of three HOPG steps lying under the $\operatorname{Pd}(0)$ nanowire circular structure is better evidenced in the digital zoom (Fig. 3e) correspondent to the black quadrant in the topographical image in Fig. 3d. The image from Fig. 3e is the amplitude image recorded simultaneously with the image in Fig. 3d. The three HOPG steps are marked with red arrows in the topographical and amplitude images and on the cross-section profile (Fig. 3f), and the vertical distance between the first and the second step is $3.14 \mathrm{~nm}$, and between the second and the third one is $1.77 \mathrm{~nm}$. From the ringed $\operatorname{Pd}(0)$ nanowire, three linear $\operatorname{Pd}(0)$ nanowires were formed, following separate step edges emerging on the surface of the HOPG electrode (Fig. 3d).

\section{Redox behaviour of palladium nanoparticles and nanowires deposited electrochemically}

The AFM topographic images clearly show the electrochemical deposition of $\operatorname{Pd}(0)$ nanoparticles and nanowires on the HOPG surface. Palladium nanoparticles and nanowires were deposited electrochemically on the GCE surface under the same experimental conditions. Electrochemical characterisation of the $\operatorname{Pd}(0)$ nanostructures deposited on GCE was carried out using $\mathrm{CV}$ with the $\mathrm{Pd}(0)$ nanostructure-modified GCE immersed in buffer solution. This presents the advantage that all redox processes occurring are from the $\operatorname{Pd}(0)$ nanostructures deposited on GCE surface with no contribution from palladium species diffusing from bulk solution. The GCE with $\operatorname{Pd}(0)$ nanoparticles enabled the study of the redox reactions of only deposited palladium.

The $\operatorname{Pd}(0)$ nanoparticles were first deposited on the GCE electrode from a concentrated solution of $100 \mu \mathrm{M} \mathrm{PdCl}_{2}$ in
pH $70.1 \mathrm{M}$ phosphate buffer after applying a conditioning potential of $-1.00 \mathrm{~V}$ for different periods of time $(5,15$ and 30 min; Fig. 4). The CVs were recorded in the potential range -0.6 to $+1.0 \mathrm{~V}$ to avoid anomalous behaviour of palladium that can occur at high potentials [41] and clearly showed the deposition of $\operatorname{Pd}(0)$ nanostructures on the GCE surface. Longer deposition times led to higher peak currents in agreement with a higher amount of $\operatorname{Pd}(0)$ deposited on the GCE surface.

The CVs in buffer solution were started at $0.0 \mathrm{~V}$ going in the positive direction, and the potential range was -0.50 to $+1.00 \mathrm{~V}$. The current started increasing at $E_{\mathrm{pa}}^{3}=+0.20 \mathrm{~V}$, peak 3 a which corresponds to $\mathrm{Pd}$ oxide formation. At higher positive potentials, a small shoulder can also be observed, peak $4_{\mathrm{a}}, E_{\mathrm{pa}}^{4}=+0.55 \mathrm{~V}$. On the reverse $\mathrm{CV}$ scan, in the negative-going direction, reduction peak 3 c occurs at $E_{\mathrm{pc}}^{3}=-0.02 \mathrm{~V}$ corresponding to reduction of the Pd oxide layer formed. Another cathodic peak $2_{\mathrm{c}}$ appears at $E_{\mathrm{pc}}^{2}=-0.45 \mathrm{~V}$, and after switching the scan direction, two more oxidation peaks were observed, peak $1_{\mathrm{a}}$ at $E_{\mathrm{pa}}^{1}=-0.50 \mathrm{~V}$ and peak $2_{\mathrm{a}}$ at $E_{\mathrm{pa}}^{2}=-0.30 \mathrm{~V}$.

To clarify the redox process corresponding to peak $1_{\mathrm{a}}$ and peak 2 a, another experiment was carried out after deposition of $\operatorname{Pd}(0)$ nanoparticles on the GCE surface at $+1.00 \mathrm{~V}$ during $30 \mathrm{~min}$. The $\mathrm{Pd}$ oxide layer is formed at $+1.00 \mathrm{~V}$, and the corresponding redox peaks $3 \mathrm{c}-3_{\mathrm{a}}$ and peak $4_{\mathrm{a}}$ were very reproducible. The CVs in Fig. 5 were recorded between a positive potential limit of $+1.00 \mathrm{~V}$ and progressively more negative potential limits of -0.25 , $-0.55,-0.60$ and $-0.65 \mathrm{~V}$.

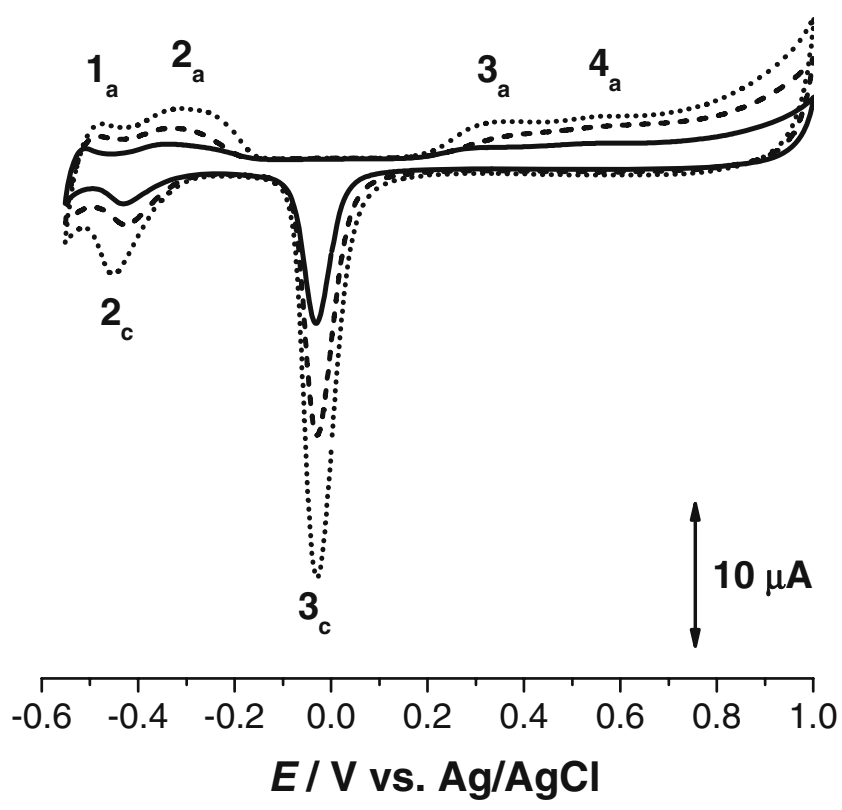

Fig. $4 \mathrm{CVs}$ of $\mathrm{Pd}(0)$ nanoparticles modified GCE surface in $\mathrm{pH} 7.0$ $0.1 \mathrm{M}$ phosphate buffer $\mathrm{N}_{2}$ saturated solution (see "Voltammetric parameters and electrochemical cells"), $\nu=100 \mathrm{mV} \mathrm{s}^{-1}$, deposited at

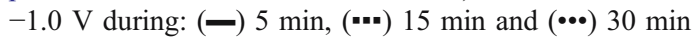




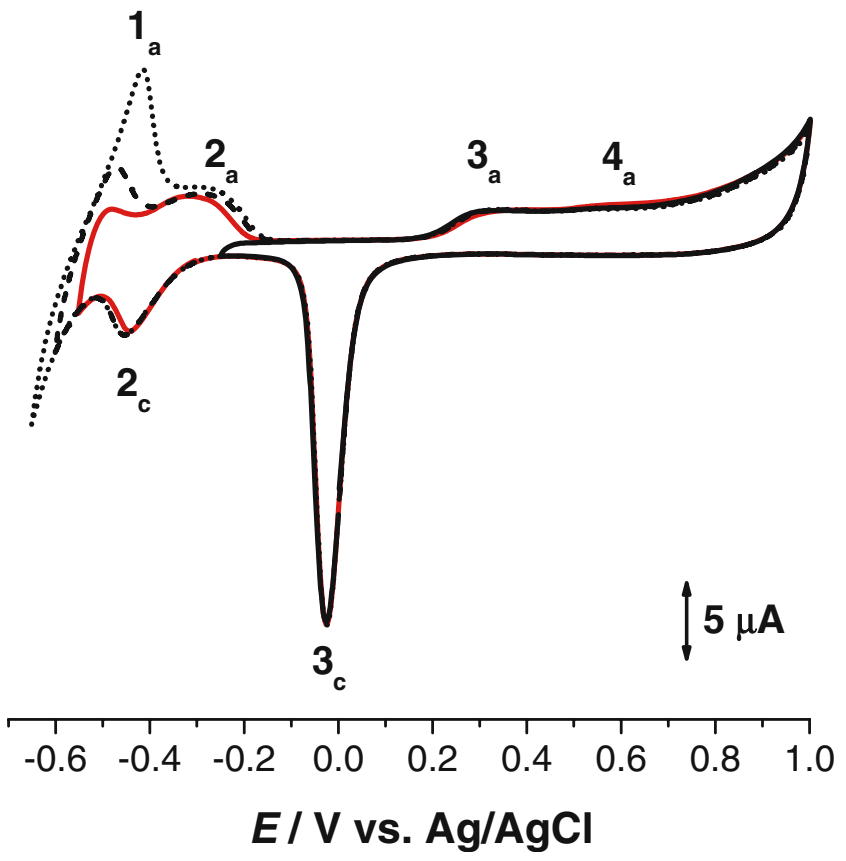

Fig. $5 \mathrm{CVs}$ of $\mathrm{Pd}(0)$ nanoparticles modified GCE surface in $\mathrm{pH} 7.0$ $0.1 \mathrm{M}$ phosphate buffer $\mathrm{N}_{2}$ saturated solution (see "Voltammetric parameters and electrochemical cells"), $\nu=100 \mathrm{mV} \mathrm{s}^{-1}$, recorded between a positive potential limit of $+1.00 \mathrm{~V}$ and a variable negative potentials limit of: $(\boldsymbol{-})-0.25 \mathrm{~V},(\boldsymbol{-})-0.55 \mathrm{~V},(\cdots)-0.60 \mathrm{~V},(\bullet \bullet)$ $-0.65 \mathrm{~V}$

In the first scan, when the scan direction was reversed at $-0.25 \mathrm{~V}$, before the occurrence of peaks $2_{\mathrm{c}}-2_{\mathrm{a}}$, no oxidation peaks at negative potentials were observed, as expected. In the next scan, which was reversed at $-0.55 \mathrm{~V}$, they appeared and show that peaks $2 \mathrm{c}-2_{\mathrm{a}}$ correspond to a reversible couple (Fig. 5). Subsequent scans, reversing at -0.60 and $-0.65 \mathrm{~V}$, showed the appearance of another oxidation peak $1_{\mathrm{a}}$ occurring at more negative potentials than peak 2 a, and the current increased as the reversing potential decreased. This effect suggests that peak $1_{\mathrm{a}}$ is due to the oxidation of hydrogen atoms adsorbed during the negative-going scan onto the $\operatorname{Pd}(0)$ nanoparticles on the GCE. However, a more negative potential limit did not affect the currents of the peaks $2_{\mathrm{c}}$ and $2_{\mathrm{a}}$, which remained almost constant (Fig. 5).

In further experiments, the CVs in buffer were recorded at a constant negative potential limit of $-0.55 \mathrm{~V}$, increasing the positive potential limit in the order: $+0.25,+0.30$, $+0.35,+0.55,+0.80$ and $+1.00 \mathrm{~V}$, to show the different steps of Pd oxide layer formation (Fig. 6). Scanning until a positive potential limit less than $+0.40 \mathrm{~V}$, the potential of the oxide film reduction peak $3 \mathrm{c}$ shifted very slightly to more positive potentials and reaches $E_{\mathrm{pc}}^{3}=+0.16 \mathrm{~V}$ (Fig. 6a). This means that at the beginning of oxide film formation, the nuclei behave reversibly, peak $3_{\mathrm{a}}, E_{\mathrm{pa}}^{3}=+0.20 \mathrm{~V}$ (Fig. 6a). However, after applying positive potential limits a

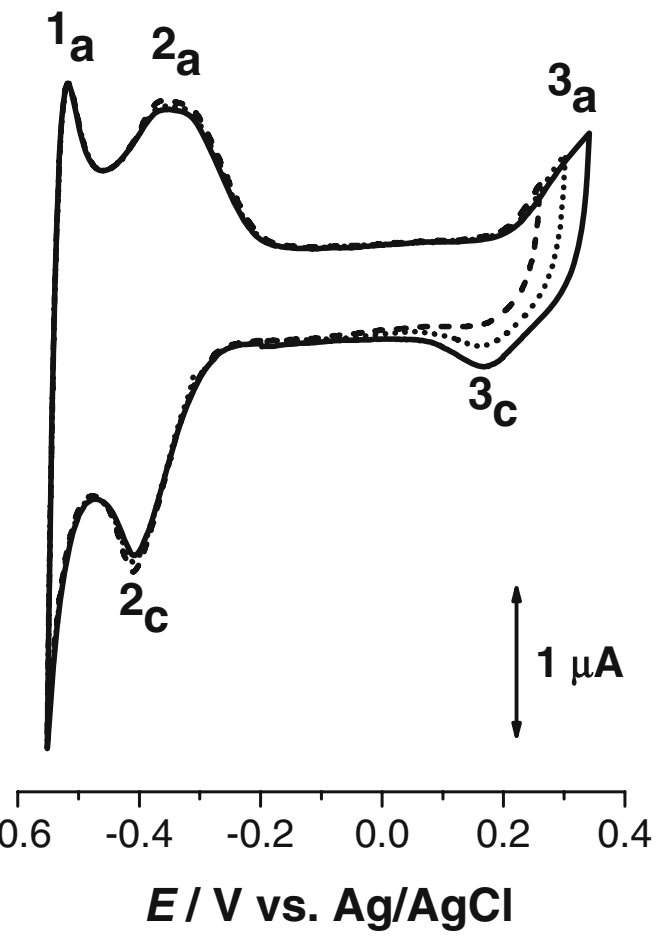

b

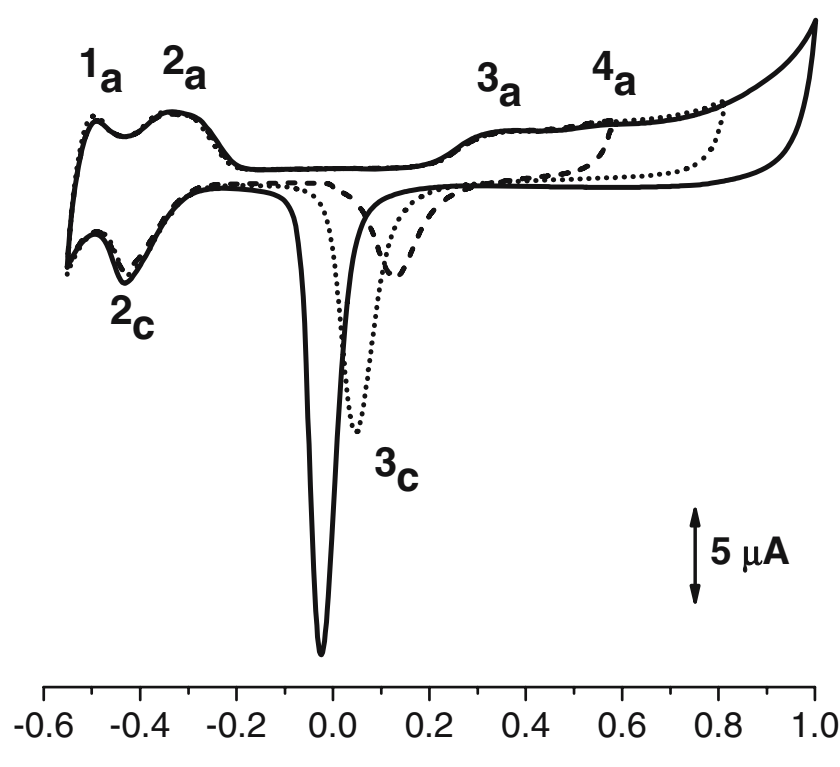

E / V vs. Ag/AgCl

Fig. $6 \mathrm{CVs}$ of $\mathrm{Pd}(0)$ nanoparticles modified GCE surface in $\mathrm{pH} 7.0$ $0.1 \mathrm{M}$ phosphate buffer $\mathrm{N}_{2}$ saturated solution (see "Voltammetric parameters and electrochemical cells"), $\nu=100 \mathrm{mV} \mathrm{s}^{-1}$, recorded between a negative potential limit of $-0.55 \mathrm{~V}$ and a variable positive potential limit of: a $(\boldsymbol{\bullet})+0.25 \mathrm{~V},(\boldsymbol{\bullet})+0.30 \mathrm{~V},(\boldsymbol{-})+0.35 \mathrm{~V} ; \mathbf{b}(\boldsymbol{\bullet})$ $+0.55 \mathrm{~V},(\bullet \bullet)+0.80 \mathrm{~V},(-)+1.00 \mathrm{~V}$

higher then $+0.40 \mathrm{~V}$ (Fig. $6 \mathrm{~b}$ ), the peak $3_{\mathrm{c}}$ potential moves towards considerably less positive values reaching $E_{\mathrm{pc}}^{3}=-0.02 \mathrm{~V}$, showing an increase in the irreversibility of the process and a very large increase in current. 
CVs were also recorded in supporting electrolytes with different $\mathrm{pH}$ values either in solutions of $100 \mu \mathrm{M} \mathrm{PdCl}_{2}$ (Fig. 7a) or after deposition of Pd onto the GCE surface (Fig. 7b), clearly showing that all palladium redox process are $\mathrm{pH}$-dependent.

In solution, two important features should be stressed. First, the $\mathrm{CV}$ obtained at acid $\mathrm{pH}$ showed an oxidation peak on the first scan at $E_{\mathrm{pa}}=+0.60 \mathrm{~V}$ (Fig. 7a). It is important to note that this peak also occurs when the scan is started at $0.0 \mathrm{~V}$ in the positive direction (not shown). This peak corresponds to the oxidation of $\mathrm{Pd}^{2+}$ with the formation of $\mathrm{Pd}^{4+}$. Second, in the $\mathrm{CV}$ obtained in alkaline $\mathrm{pH}$, a small cathodic peak occurred on the first scan at $E_{\mathrm{pc}}=-0.95 \mathrm{~V}$ (Fig. 7a). This peak is due to the reduction of $\mathrm{Pd}^{2+}$ and the electrochemical deposition of $\operatorname{Pd}(0)$ nanoparticles on the GCE.

$\mathrm{CVs}$ at different values of $\mathrm{pH}$ of deposited $\operatorname{Pd}(0)$ nanoparticles on the GCE surface (Fig. 7b) show the palladium redox process much more clearly. In acid electrolyte, the CVs were similar to those obtained in neutral media. Nevertheless, higher peaks were obtained in acid solutions probably due to the higher concentration of $\mathrm{H}^{+}$(aq). A noticeable difference was observed in alkaline electrolyte where all the currents were smaller. Palladium oxide layer formation was very well defined $+0.40 \mathrm{~V}$, but on the negative-going scan, the palladium oxide layer reduction peak occurred with a much smaller current. Moreover, peak $2_{\mathrm{c}}$ occurs at lower potentials, but no evidence of a reversible oxidation was observed. These facts could be explained taking into consideration the formation of a more stable palladium oxide/hydroxide layer on the electrode surface in alkaline media caused by the much higher concentration of $\mathrm{OH}^{-}$at the electrode/solution interface.

\section{Impedance spectroscopy}

Electrochemical impedance spectroscopy measurements were carried out to clarify the behaviour of the palladium nanostructures electrochemically deposited on the GCE, and the results will be compared with the voltammetric data. Impedance spectra of deposited $\operatorname{Pd}(0)$ nanoparticles on the GCE surface (Fig. 8) were recorded in $\mathrm{pH} 70.1 \mathrm{M}$ phosphate buffer at different potentials corresponding to the hydrogen evolution region, as well as at potentials matching the premonolayer oxidation and oxide layer formation.

On the complex plane plot obtained at low potentials, in the hydrogen evolution region, the semicircle obtained in the high-frequency range corresponds to a charge transfer

Fig. $7 \mathrm{CVs}$ in $\mathrm{N}_{2}$ saturated electrolytes with different $\mathrm{pH}$ values, $\nu=100 \mathrm{mV} \mathrm{s}^{-1}$ : a in $100 \mu \mathrm{M} \mathrm{PdCl}_{2} ; \mathbf{b}$ of $\operatorname{Pd}(0)$ nanoparticles on the GCE surface (see "Voltammetric parameters and electrochemical cells")

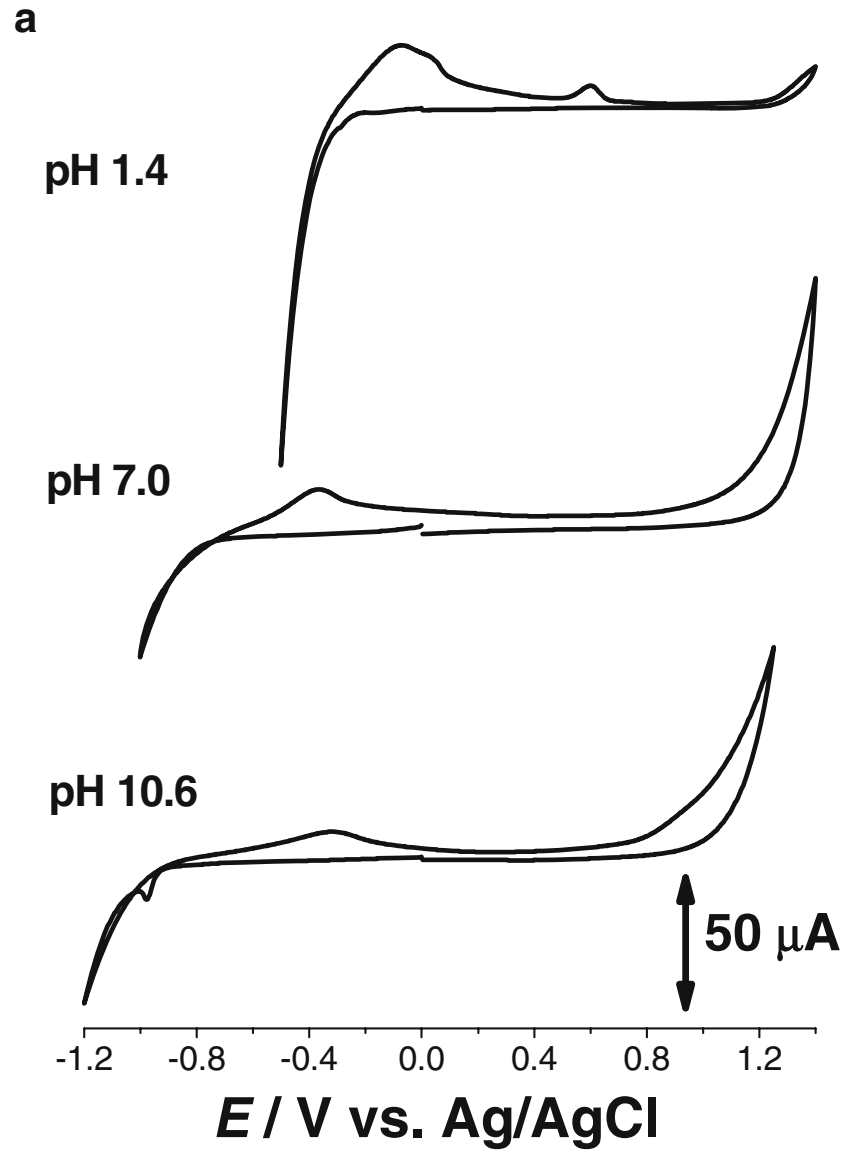

b

pH 1.4
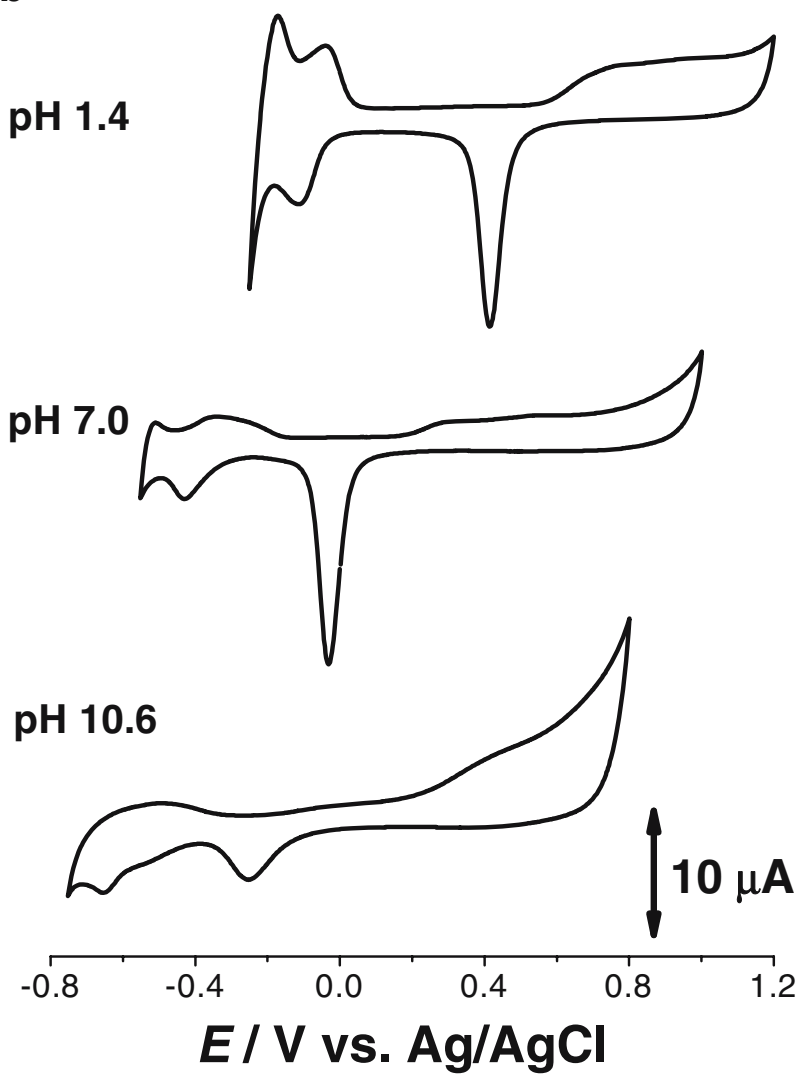


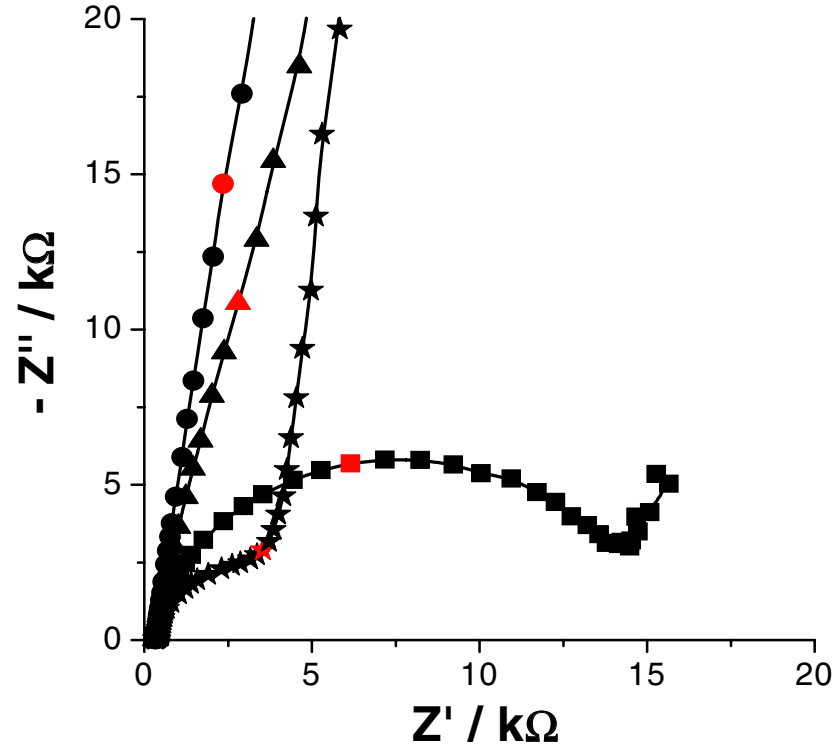

Fig. 8 Impedance spectra of $\operatorname{Pd}(0)$ nanoparticles modified GCE surface (see "Voltammetric parameters and electrochemical cells") in pH 7.0 0.1 M phosphate buffer at: (filled square) $-0.55 \mathrm{~V}$, (filled star) $-0.40 \mathrm{~V}$, (filled triangle) $0.0 \mathrm{~V}$ and (filled circle) $+0.80 \mathrm{~V}$. The red points represent a frequency of $f=5.6 \mathrm{~Hz}$

reaction. The lowest value for the charge transfer resistance was obtained at $-1.00 \mathrm{~V}$ when compared with the value obtained at a potential of $-0.55 \mathrm{~V}$, in agreement with the higher current obtained in voltammetric studies. For lower frequency values, the Warburg impedance represents the diffusion of hydrogen through the $\operatorname{Pd}(0)$ nanoparticle lattice.

The next impedance spectrum was recorded at an applied potential of $-0.40 \mathrm{~V}$ corresponding to the end of the hydrogen absorption region and just before the occurrence of peak 2 . The complex plane plot also shows a semicircle at high frequencies in agreement with the incipient oxidation of palladium metal nanoparticles. At lower frequencies, a capacitive behaviour was observed, which can be attributed to a hydrous oxide monolayer formed on the GCE surface.

The impedance spectra obtained at higher positive potentials showed a capacitive behaviour typical of adsorbed films. Increasing the applied potential to $+0.80 \mathrm{~V}$, an enhancement in the capacitive behaviour was clearly observed.

\section{Discussion}

Although no charge transfer reaction can be observed on the first negative-going scan in Fig. 1a and b, the occurrence of peak $1_{\mathrm{a}}$ on the first positive-going scan can be explained by the reduction of $\mathrm{Pd}^{2+}$ ions to $\mathrm{Pd}(0)$ in a redox mechanism that involves the transfer of two electrons. Effectively, due to the high negative peak potential for glassy carbon only in $\mathrm{pH} 10.6100 \mu \mathrm{M} \mathrm{PdCl}_{2}$ solutions (Fig. 7a), a small peak on the first recorded $\mathrm{CV}$, as evidence of the reduction of $\mathrm{Pd}^{2+}$ ions, was observed. After oxidation of $\mathrm{Pd}^{2+}$, a layer of palladium metal nanoparticles was formed on the electrode surface and clearly shown by AFM (Figs. 2 and 3).

The shape of the peaks $1_{\mathrm{a}}^{\prime}$ and $1_{\mathrm{a}}^{\prime \prime}$ in the voltammograms in Fig. $1 b$ are explained taking into consideration one of the most important properties of Pd which is the ability to adsorb, on its surface, and absorb, within its lattice, hydrogen.

On scanning the potential in the negative direction, Pd metal is formed and deposited on the electrode surface, and when the potential reaches sufficiently negative values (Figs. 1a and 4), protons are reduced to hydrogen, which is adsorbed on the palladium surface and absorbed into the palladium lattice, and scanning in the positive direction, peak $1_{\mathrm{a}}$, appears due to the oxidation of hydrogen atoms. At a more negative applied potential of $-1.00 \mathrm{~V}$ and increasing the number of scans in $\mathrm{Pd}^{2+}$ solution, more Pd metal is deposited on the GCE surface, which allows the incorporation of more hydrogen into the Pd lattice (Fig. 1b). The consequence is the possibility of a good separation of peak $1_{\mathrm{a}}$ in two peaks, $1_{\mathrm{a}}^{\prime}$ and $1_{\mathrm{a}}$, corresponding to the oxidation of hydrogen atoms in the adsorbed and the absorbed layers within the palladium lattice. AFM confirmed that $\operatorname{Pd}(0)$ nanoparticles were formed during the CVs performed at negative potentials (Fig. 2a and b).

When the potential was scanned to high positive values, $E>+1.20 \mathrm{~V}$, the splitting of peak $1_{\mathrm{a}}$ also occurred (Fig. 1b). This is explained by identifying peak $1_{a}^{\prime}$ with the oxidation of hydrogen adsorbed on the surface of palladium and peak $1_{\mathrm{a}}^{\prime \prime}$ with the oxidation of hydrogen absorbed into the palladium metal lattice. This effect was not observed when the potential was scanned only in the negative potential region, between 0 and $-1.00 \mathrm{~V}$ (not shown), or when the potential was scanned to $E<+1.20 \mathrm{~V}$ (Fig. 6). Thus, it can be concluded that splitting of peak $1_{\mathrm{a}}$ is directly related with disruption of the palladium lattice or of the palladium oxide layer, and this occurs at high positive applied potentials [41]. For this reason, all other CV experiments were carried out at $E<+1.20 \mathrm{~V}$.

At positive potentials, $\operatorname{Pd}(0)$ nanoparticles deposited on the GCE surface are oxidized to $\mathrm{Pd}^{2+}$ or $\mathrm{Pd}^{4+}$ and form a palladium oxide layer. The $\mathrm{PdO}$ starts being formed at $+0.20 \mathrm{~V}$ (Fig. 4). Additionally, it was shown by recording CVs in acidic solutions that higher oxidation states of Pd, most probably $\mathrm{Pd}^{4+}$, were also involved (Fig. 7a), leading to the formation of a second $\mathrm{PdO}_{2}$ layer [42], which can explain the occurrence of the small oxidation plateau of peak $4_{\mathrm{a}}$ at $E_{\mathrm{pa}}^{4}=-0.55 \mathrm{~V}$ (Fig. 5). A peak corresponding to the formation of palladium oxide was also observed on the first $\mathrm{CV}$ scan from zero towards positive potentials in the $\mathrm{PdCl}_{2}$ solution in acid media (Fig. 7a). 
The Pd oxides are reduced on the negative-going scans, leading back to Pd metal. Depending on the positive potential limit, the Pd oxide layer reduction occurs in a reversible or irreversible manner. When the scan was inverted at $E<+0.40 \mathrm{~V}$, the $\mathrm{PdO}$ reduction undergoes a reversible reduction. However, for $E>+0.40 \mathrm{~V}$, the reduction of the palladium oxide layer behaves irreversibly, and this can be explained by the formation of a $\mathrm{PdO}_{2}$ oxide layer.

Scanning the potential in the positive direction (Fig. 2c and d), until $E=+0.90 \mathrm{~V}$, two different size adsorbed structures were observed in the AFM images related with the adsorption of large $\operatorname{Pd}(0)$ nanoparticles and uniformly distributed smaller palladium oxide nanoparticles on the HOPG surface. The PdO and $\mathrm{PdO}_{2}$ formed adsorb on the plane terraces of the HOPG and can also act as nucleation sites for the growth of $\operatorname{Pd}(0)$ nanoparticles. This explains the more uniform distribution of the nanoparticles over the electrode surface formed at $E=+0.90 \mathrm{~V}$ when compared with the $\operatorname{Pd}(0)$ nanoparticles and nanowires grown at $E=-1.00 \mathrm{~V}$ that are preferentially deposited on the HOPG step edges (Figs. 2a,b and 3).

Experiments carried out with $\operatorname{Pd}(0)$ nanoparticles on the GCE surface in buffer electrolyte, i.e. with no diffusing species from bulk solution, have clearly indicated that the formation of the palladium oxide layer begins at negative potentials, peak $2_{\mathrm{a}}-2_{\mathrm{c}}$ (Figs. 5 and 6 ). This process is due to the existence of highly active palladium metal adatoms that can undergo a reversible adatom/incipient oxide formation in the hydrogen adsorption region of palladium. Such a transition has been postulated earlier [43], but more recent works showed experimental evidence of the formation of a pre-monolayer oxide on the surface of metal palladium [41] and also of other noble metals [44].

Pre-monolayer oxidation processes at metal surfaces may be understood on the basis of metal nanoparticles [43]. The important feature is that as these particles are extremely small, the redox potential is size dependent. This has been explained taking into account that the isolated metal atom is a highly electropositive species, an effect attributed to the decrease of lattice stabilization energy [23$25,43]$ or to the presence of quantum confinement effects [45]. Based on these, it is suggested that the dispersed palladium metal atoms on the electrode surface are responsible for the pre-monolayer oxidation effects.

Thus, the PdO layer formation is initiated with the formation of the pre-monolayer oxide film on the electrode surface in a fast discharge of either $\mathrm{H}_{2} \mathrm{O}$ or $\mathrm{OH}^{-}$to produce $\mathrm{PdOH}$ species. At the monolayer level, oxide films on noble metal surfaces can be irreversibly transformed into a more stable structure either through a dismutation process called the place exchange mechanism [26, 27] or through an electrochemical process that involves the transfer of electrons and protons with the participation of $\mathrm{OH}^{-}$[46]. Independently of the mechanism, the result of these processes is the formation of a PdO film onto the electrode surface (Fig. 5) starting with an increase in current at about $+0.20 \mathrm{~V}$ that continues with a plateau.

Furthermore, in higher resolution AFM images, scanning the surface for the first time between -0.5 and $0.0 \mathrm{~V}$ (Fig. 2a and $b$ ), very small deposits of palladium on the basal plane of the HOPG can be observed, which are easily removed by the AFM tip while scanning the sample. These small deposits are probably related with the formation of the Pd pre-monolayer oxide film that occurs at negative potentials.

\section{Conclusions}

The ex situ and in situ AFM and voltammetric experiments showed that nanoparticles and nanowires of palladium can be electrodeposited on the surface of carbon electrodes (HOPG and GCE), being preferentially attached to surface defects. The AFM study enabled the determination of the dimensions of the Pd nanostructures.

The palladium nanoparticles and nanowires electrochemically deposited onto a carbon surface behave differently with respect to the $\mathrm{pH}$ of the electrolyte buffer solution. In acid or mild acid solutions under applied negative potentials, hydrogen can be adsorbed/absorbed onto/into the palladium lattice. By controlling the applied negative potentials, different quantities of hydrogen can be incorporated, and this process is followed by analysing the oxidation peak of hydrogen. At high positive potentials, $\operatorname{Pd}(0)$ nanoparticles on the electrode surface undergo oxidation, and the formation of an oxide layer can be observed. AFM images showed that $\mathrm{PdO}$ and $\mathrm{PdO}_{2}$ oxides formed on the surface may act as nucleation points for Pd metal growth, increasing the metal electrode surface coverage. Due to the existence of higher Pd oxidation states, the growth of $\mathrm{PdO}_{2}$ film is possible, and this reaction is irreversible. It has been shown that the formation of $\mathrm{Pd}$ pre-monolayer oxide film begins at negative potentials, although well separated from the hydrogen evolution region. This effect is related to the presence of highly active metal palladium adatoms on the electrode surface. These atoms can undergo a reversible adatom/ incipient oxide formation at much lower potentials when compared with classical oxide layer formation, a highly relevant effect in electrocatalytic processes.

Acknowledgements Financial support from Fundação para a Ciência e Tecnologia (FCT), Post-Doctoral Grants SFRH/BPD/18824/2004 (V.C. Diculescu), SFRH/BPD/27087/2006 (A.M. Chiorcea-Paquim), Ph.D. Grant SFRH/BD/18914/2004 (O. Corduneanu), POCI 2010 (co-financed by the European Community Fund FEDER), ICEMS (Research Unit 103), is gratefully acknowledged. 


\section{References}

1. Harrison BS, Atala A (2007) Biomaterials 28:344

2. He X, Wu F, Zheng M (2006) DOI 10.1016/j.diamond.2006.06.011

3. Kohli P, Wirtz M, Martin CR (2004) Electroanalysis 16:9

4. Welch CM, Compton RG (2006) Anal Bioanal Chem 384:601

5. Katz E, Willner I, Wang J (2004) Electroanalysis 16:19

6. Simm AO, Ward-Jones S, Banks CE, Compton RG (2005) Anal Sci 21:667

7. Raj CR, Okajima T, Ohsaka T (2003) J Electroanal Chem 543:127

8. Liu H, Favier F, Ng K, Zach MP, Penner RM (2001) Electrochim Acta 47:671

9. Penner RM (2002) J Phys Chem B 106:3339

10. Walter EC, Murray BJ, Favier F, Kaltenpoth G, Grunze, M, Penner RM (2002) J Phys Chem B 106:11407

11. Kawde A-N, Wang J (2004) Electroanalysis 16:101

12. Willner B, Katz E, Willner I (2006) Curr Opin Biotech DOI 10.1016/j.copbio.2006.10.008

13. Martínez-Sánchez R, Reyes-Gasga J, Caudillo R, García-Gutierrez DI, Márquez-Lucero A, Estrada-Guel I, Mendoza-Ruiz DC, José Yacaman M (2006) J Alloy Compd DOI 10.1016/j.jallcom.2006.08.051

14. Dávila-Martínez RE, Cueto LF, Sánchez EM (2006) Surf Sci 600:3427

15. Ng KH, Liu H, Penner RM (2000) Langmuir 16:4016

16. Mayrhofer KJJ, Arenz M, Blizanac BB, Stamenkovic V, Ross PN, Markovic NM (2005) Electrochim Acta 50:5144

17. Zoval JV, Lee J, Gorer S, Penner RM (1998) J Phys Chem B 102:1166

18. You T, Niwa O, Chen Z, Hayashi K, Tomita M, Hirono S (2003) Anal Chem 75:5191

19. Xu C, Wu G, Liu Z, Wu D, Meek TT, Han Q (2004) Mater Res Bull 39:1499

20. Male KB, Hrapovic S, Liu Y, Wang D, Luong JHT (2004) Anal Chim Acta 516:35

21. Sun YP, Li XQ, Cao J, Zhang WX, Wang HP (2006) Adv Colloid Interface Sci 120:47
22. Charles E, Sykes H, Fernandez-Torres LC, Nanayakkara SU, Mantooth BA, Nevin RM, Weiss PS (2005) Proc Natl Acad Sci USA 102:17907

23. Burke LD, Casey JK (1993) J Electrochem Soc 140:1284

24. Burke LD, Casey JK (1993) J Electrochem Soc 140:1292

25. Burke LD, Casey JK (1993) J Appl Electrochem 23:573

26. Bolzán AE (1995) J Electroanal Chem 380:127

27. Chierchie T, Mayer C, Lorentz WJ (1982) J Electroanal Chem 135:211

28. Gossner K, Mizera E (1981) J Electroanal Chem 125:347

29. Baldauf M, Kolb DM (1993) Electrochim Acta 38:2145

30. Naohara H, Ye S, Uosaki K (1998) J Phys Chem B 102:4366

31. Lubert K-H, Guttman M, Beyer L (1999) J Electroanal Chem 462:174

32. Lubert K-H, Guttman M, Beyer L, Kalcher K (2001) Electrochem Commun 3:102

33. Li F, Zhang B, Dong S, Wang E (1997) Electrochim Acta 42:2563

34. Pattabiraman R (1997) Appl Catal A Gen 153:9

35. Batchelor-McAuley C, Banks CE, Simm AO, Jones TGJ, Compton RG (2006) Chem Phys Chem 7:1081

36. Fournée V, Barrow JA, Shimoda M, Ross AR, Lograsso TA, Thiel PA, Tsao AP (2003) Surf Sci 541:147

37. Ji X, Banks CE, Xi W, Wilkins SJ, Compton RG (2006) J Phys Chem B 110:22306

38. Atshabar MZ, Banerji D, Singamaneni S, Bliznuyuk V (2004) Nanotechnology 15:374

39. Handbook of chemistry and physics http://www.hbcpnetbase.com/

40. Czrewinski A, Marassi R, Zamponi S (1991) J Electroanal Chem 316:211

41. Burke LD, Nagle LC (1999) J Electroanal Chem 461:52

42. Burke LD, Casey JK (1992) Electrochim Acta 37:1817

43. Markovic NM, Sarrat ST, Gasteiger HA, Ross PN (1996) J Chem Soc Faraday Trans 92:3719

44. Tani T (1989) Phys Today 36:36

45. Bagotzky VS, Tarasevich MR (1979) J Electroanal Chem 101:1

46. Kim KS, Gossmann AF, Winograd N (1974) Anal Chem 46:197 